These selected abstracts and titles from the world literature are arranged in the following sections:

Syphilis and other treponematoses

(Clinical and therapy; serology and biological falsepositive phenomenon; pathology and experimental)

Gonorrhoea

(Clinical; microbiology; therapy)

Non-specific genital infection

Reiter's disease
Trichomoniasis
Candidosis

Genital herpes

Other sexually transmitted diseases

Public health and social aspects

Miscellaneous
Syphilis and other

treponematoses (Clinical and therapy)

\section{Neurosyphilis today}

L. LUXON, A. J. LEES, AND R. J. GREENWOOD (1979). Lancet, 1, 90-93

In 17 cases of neurosyphilis, referred from nine other hospitals to the National Hospital, Queen's Square, London, the clinical presentations were diverse, and some are described in detail. Pupillary abnormalities were the commonest sign in the series (nine of 17), including three cases of Argyll-Robertson pupils. External ophthalmoplegias, optic neuritis, optic atrophy, choroidoretinitis, and papilloedema were also described. Classical tabes dorsalis, tabo-paresis, eighth nerve lesions, and complex cerebrospinal involvement were documented, but many cases had more than one of these features. The authors point out that the clinical features of these patients did not differ from those described in the pre-antibiotic era. Diagnosis was confirmed by positive results to specific treponemal tests on specimens of CSF. Results of reagin tests on CSF samples suggest that these may be a less sensitive detector of neurosyphilis than the TPHA and FTA. Ten of the patients had previously received antibiotic treatment for other illnesses.

The response to penicillin, where documented, seemed on the whole better in ocular or otological disease than in spinal or cerebral disease. There was no effect on the Argyll-Robertson pupils. It would, however, be helpful to have more information on the dosage used and the stage of infection when treated, particularly in the ocular or otological cases. This is a very useful paper for young physicians of the antibiotic era who have seen little classical neurosyphilis. It is a pity it is not presented in greater detail.

David Goldmeier

Bell's palsy and secondary syphilis: CSF spirochaetes detected by immunofluorescence

L. E. DAVIS AND S. SPERRY (1978). Annals of Neurology, 4, 378-380

The history of a 30-year-old man, who initially presented with a mild headache, right-sided facial weakness, and a maculopapular rash on the trunk and extremities, is reported from Albuquerque, New Mexico. Bell's palsy was diagnosed, and he was given prednisolone $60 \mathrm{mg} / \mathrm{day}$ for two weeks. The rash disappeared but the headaches continued and a mild tinnitus developed. There was no history of a primary syphilitic lesion. Six weeks later the patient was re-examined. There was a rightsided peripheral facial paralysis and a patchy alopecia. Other cranial nerves were normal apart from a bilateral high-tone deafness.

Examination of the CSF at this time showed a raised pressure, 125 white cells $/ \mathrm{mm}^{3}$ (80\% lymphocytes), and a raised protein $(1.060 \mathrm{~g} / \mathrm{l})$. The CSF-VDRL test was reactive undiluted and the CSF-FTAABS test showed $1+$ fluorescence. Serum tests gave RPR positive results $(1 / 128)$ and the FTA-ABS test strongly positive results. The patient was treated for three weeks with penicillin (the dosage and preparation are not recorded). One week later movement had returned to the right half of the face, and the headaches and tinnitus had gone. The CSF-VDRL test became 0 non-reactive, and the CSF-FTA-ABS test was borderline reactive. The $\mathrm{CSF}-$ biochemical results became normal.

A centrifuged specimen of the CSF taken before treatment showed 15 treponeme-like organisms in the deposit. These gave $\overrightarrow{0}$ specific fluorescence when stained 7 indirectly with known positive serum. Adequate controls were used. No treponeme-like organisms were seen in the post-treatment specimen similarly examined.

This paper re-emphasises the value of $a \frac{2}{D}$ close working relationship between otorhinolaryngologists and venereologists.

G. D. Morrison

\section{Syphilis (pathology and experimental)}

Influence of oxygen tension, sulphydryl compounds and serum on the motility and $ᄋ$ virulence of Treponema pallidum (Nichols strain) in a cell-free system

S. J. NORRIS, J. N. MILLER, J. A. SYKES, AND T. J. FITZGERALD (1978). Infection and Immunity, 22, 689-697

The survival of virulent Treponema pallidum in Eagle's MEM medium with various additives was studied under aerobic 0 and anaerobic conditions and in the $\frac{c}{\Phi}$ presence of $3 \%$ oxygen. The addition of $\mathscr{\varrho}$ $50 \%$ inactivated normal rabbit serum prolonged motility under anaerobic ${ }^{\circ}$ conditions and in the presence of $3 \% \mathrm{O}_{2} \underset{\mathbb{D}}{\stackrel{D}{(10}}$ but not in aerobic cultures. The addition of L-cysteine did not help survival but $\stackrel{\mathbb{Q}}{\sigma}$ 
glutathione had some effect. Dithiothreitol (DTT) prolonged survival for up to 180 hours in an environment of $3 \% \mathrm{O}_{2}$ but had no effect in the anaerobic system; its effect was decreased in the presence of L-cysteine and glutathione. The optimum concentration of DTT was found to be 1.0 mmol. In further experiments this concentration was shown to promote retention of virulence of the organism. The basal medium plus serum and DTT was found suitable for the growth of cultures of normal rabbit testis cells in the presence of $3 \% \mathrm{O}_{2}$ but not under anaerobic conditions.

The mode of action of sulphydryl compounds and DTT is discussed. The results obtained suggest that $T$. pallidum is a microaerophilic organism rather than a true anaerobe.

A. E. Wilkinson

(Reprinted from Abstracts on Hygiene by permission of the Editor.)

Capacity of virulent Treponema pallidum (Nichols) for deoxyribonucleic acid synthesis

J. B. BASEMAN, J. C. NICHOLS, AND

S. MOGERLEY (1979). Infection and Immunity, 23, 392-437

Gonorrhoea (Microbiology)

Serology of Neisseria gonorrhoeae. Demonstration of strain-specific antigens by immunoelectrophoresis, immunofluorescence and co-agglutination techniques

D. DANIELSSON AND E. SANDSTRÖM

(1979). Acta Pathologica et

Microbiologica Scandinavica, Sect B, 87, 55-64

Four strains of gonococci isolated from two patients with complicated and two with uncomplicated infections were studied. The first two strains had the same, and the last two different, auxotypes. Antisera were raised against these strains in rabbits and tested against sonicates of the various strains by crossed immunoelectrophoresis, crossed line and rocket electrophoresis, and by indirect immunofluorescence and coagglutination tests with intact organisms. Strain-specific antigens were demonstrated; these resisted heating at $100^{\circ} \mathrm{C}$ but not at $120^{\circ} \mathrm{C}$ and were probably constituents of the outer membranes. It was noted that in the co-agglutination test staphylococci coated with unabsorbed or absorbed antibodies gave weak or negative results with untreated gonococci of T3/T4 colonial types but strong reactions with $\mathrm{T} 2$ organisms. After heating T3/T4 gonococci at $100^{\circ} \mathrm{C}$ for an hour they reacted as strongly as T2 organisms.

A. E. Wilkinson

(Reprinted from Abstracts on Hygiene by permission of the Editor.)

Auxotypes and antibiotic susceptibility patterns of Neisseria gonorrhoeae from disseminated and local infections

S. E. THOMPSON, G. REYNOLDS, H. B. SHORT, C. THORNSBERRY, J. W. BIDDLE, N. F. JACOBS, M. F. REIN, A. A. ZEIDI, F. E. YOUNG, AND J. A. SHULMAN (1978). Sexually Transmitted Diseases, 5, 127-131

The arginine-hypoxanthine-uracil auxotype has been linked with the propensity of gonococci to cause disseminated infections. Gonococci recovered from 25 patients with disseminated gonococcal infections were compared with gonococci recovered from matched controls, patients with uncomplicated gonorrhoea selected during the same month. Minimum inhibitory concentrations of penicillin, tetracycline, erythromycin, and ampicillin, and the nutritional requirements (auxotypes) for proline alone, arginine alone, arginine, hypoxanthine and uracil together, serine alone and cysteine-cystine (wild type) were analysed by discriminant analysis. Significant susceptibility to penicillin characterised strains causing disseminated infections, and a proline requirement was the most common auxotype $(48 \%)$ among strains isolated in Atlanta. Together the minimum inhibitory concentration of penicillin and the proline auxotype best separated the strains causing disseminated gonoccal infections from those causing uncomplicated gonorrhoea. The argininehypoxanthine-uracil auxotype was found in only $24 \%$ of strains causing disseminated infections. A trait other than auxotype must determine the capacity of the organisms to disseminate.

Authors' summary

Cell envelope of Neisseria gonorrhoeae CS7: peptidoglycan-protein complex

B. H. HEBELER, W. WONG, S. A. MORSE, AND F. E. YOUNG, (1979). Infection and

Immunity, 23, 353-391
Studies on gonococcus infection, XVII. IgA cleaving protease in vaginal washings from women with gonorrhoea

H. M. BLAKE, K. K. HOLMES, AND J. SWANSON (1979). Journal of Infectious Diseases, 139 $\overrightarrow{\overline{\bar{C}}}$ 89-92

Non-specific genital infection क

Diagnosis and etiology of non-gonococcalurethritis

S. L. SWARTZ, S. J. KRAUS, K. L. HERRMANN, M. D. STARGEL, W. J. BROWN, AND S. D. ALLENO (1978). Journal of Infectious Diseases, 138 445-455

The observation of more than four poly morphonuclear cells (PMN) per high poweP field (hpf) in Gram-stained smears of urethral secretions was found to differentiate patients with urethritis from patients without urethritis. A urethra discharge was present in $78 \%$ of patient with nongonococcal urethritis (NGU) Dysuria without demonstrable urethrate discharge and with fewer than four PMN/hpf did not appear to fit into the NGU spectrum. NGU is now defined t\$ include men who have negative urethraf culture results for Neisseria gonorrhoea with a urethral discharge or more than foum PMN/hpf in their urethral smears or both The finding of more than four PMN/hpf in the urethral smears of $22 \%$ o asymptomatic sexually active men wit more than one sexual partner (polygamous controls) suggests that asymptomatic NG广 is not uncommon. Chlamydia trachomatis was isolated significantly more frequently from the NGU study group than from the control group $(\mathrm{P}<0 \cdot 001)$. This study adds Corynebacterium vaginale (Haemophilus vaginalis), group B streptococci, and yeast to the list of sexually transmitted microe organisms that are not aetiologicaf determinants of NGU.

Authors' summar

Etiologies of postgonococcal urethritis in $\mathrm{N}$ homosexual and heterosexual men: roles of Chlamydia trachomatis and Ureaplasma urealyticum

W. R. BOWIE, E. R. ALEXANDER, AND

K. K. HOLMES (1978). Sexually Transmitted

Diseases, 5, 151-154

Before treatment for urethral gonorrhoea

Chlamydia trachomatis was isolated frore

$18 \%$ and Ureaplasma urealyticum from 
$37 \%$ of 121 men. C. trachomatis was recovered from none of $\mathbf{1 8}$ homosexual men who had gonorrhoea and from 22 of 95 heterosexual men who had gonorrhoea $(P<0.05)$. After treatment with a penicillin, postgonococcal urethritis occurred significantly more often in heterosexual than in homosexual men $(\mathrm{P}<0.002)$. Postgonococcal urethritis developed in all men from whom $C$. trachomatis was isolated. Among men without $U$. urealyticum infection, postgonococcal urethritis was significantly associated with C. trachomatis infection $(\mathrm{P}<0 \cdot 02)$. Among men without $C$. trachomatis infection postgonococcal urethritis was less closely associated with $U$. urealyticum infection $(0 \cdot 1>\mathrm{P}>0 \cdot 25)$. Postgonococcal urethritis was least frequent among men who had neither $C$. trachomatis nor $U$. urealyticum infection.

Authors' summary

\section{Chlamydia trachomatis cervicitis in gynecologic outpatients \\ K. T. RIPA, L. SVENSSON, P.-A. MÅRDH, AND L. WESTRÖM (1978). Obstetrics and Gynecology, 52, 608-702}

Symptoms suggestive of a lower genital tract infection (LGTI) are common complaints in women who consult gynaecologists. Sexually transmitted microorganisms, such as Chlamydia trachomatis, are responsible for a substantial proportion of LGTI. This study was performed to establish the frequency of LGTI caused by C. trachomatis in women attending a gynaecological outpatient clinic. Of 170 women with LGTI, $32.9 \%$ harboured one or more of these organisms: $C$. trachomatis was found in $19 \cdot 3 \%, N$. gonorrhoeae in $4 \cdot 7 \%$, and $T$. vaginalis in $25 \cdot 9 \%$. The results of the isolation studies were correlated with clinical signs and symptoms. In women under 25 years of age, chlamydial cervicitis was found significantly more often in users of oral contraceptives than in non-users. In women not taking such drugs, cervical erosion was found more often in chlamydiae-positive than in chlamydiae-negative women. Since clinical examination failed to show any characteristic signs in cases of chlamydial infection, it was not possible to distinguish a chlamydial from a gonococcal infection. This study also reports the successful treatment of 15 women affected by chlamydial cervicitis with doxycycline or trimethoprim-sulphamethoxazole.

Authors' summary
Chlamydial pneumonitis

C. ARTH, B. VON SCHMIDT, M. GROSSMAN, AND J. SCHACHTER (1978). Journal of Pediatrics, 93, 447-449

Chlamydia trachomatis and pneumonia in infants: report of two cases

J. A. EMBIL, R. L. OZERE, AND S.W. MACDONALD (1978). Canadian Medical Association, 119, 1199-1204

Infection with Chlamydia trachomatis: involvement of multiple anatomic sites in neonates

J. SCHACHTER, M. GROSSMAN, J. HOLT, R. SWEET, AND S. SPECTOR (1979). Journal of Infectious Diseases, 139, 232-234

Experimental nasopharyngitis and pneumonia caused by Chlamydia trachomatis in infant baboons;

histopathologic comparison with a case in a human infant

H. R. HARRISON, E. RUSSELL ALEXANDER,

W. T. CHIANG, W. E. GIDDENS JNR. J. T. BOYCE, D. BENJAMIN, AND J. L. GALE (1979). Journal of Infectious Diseases, 139, 141-146

These four papers on neonatal chlamydial infection may be considered together. Infantile pneumonia associated with $C$. trachomatis was first defined clinically by Beem and Saxon (1977). Characteristically it presents at the age of 4-6 weeks as an afebrile illness with tachypnoea and a paroxysmal staccato cough. Chest $x$-rays show diffusely distributed interstitial and alveolar infiltrates, and IgG and IgM concentrations are often raised. $C$. trachomatis is usually recovered from nasopharyngeal and tracheal aspirates, and occasionally from other sites, and there are elevated antichlamydial antibody titres as measured by microimmunofluorescence. One half of these infants have conjunctival involvement according to history, examination, or culture. Frommell et al. (1977) isolated the organism from lung tissue, but their patient also had a cytomegalovirus infection.

In the infant described by Arth et al., working in San Francisco, the characteristic clinical features were present. Although there was a history of ocular infection a few days after birth (treated with sulfisoxazole), chlamydiae were not isolated from ocular or pharyngeal specimens. However, an open biopsy specimen of lung tissue, which showed near obliteration of involved alveoli with round cells and widespread necrotising bronchiolitis, yielded chlamydiae on culture. The patient recovered completely after treatment with erythromycin.

Embil et al. report two further cases of chlamydial pneumonia in infants from Halifax, Canada. In both, the illness was most severe at age 4 weeks. One had a history of conjuctivitis, and both presented with staccato cough and tachypnoea. Chest $x$-rays showed hyperexpansion and pulmonary infiltration, and the IgM concentrations were markedly raised. $C$. trachomatis was recovered from nasopharyngeal and throat swabs from both infants, and chlamydial antibody titres were raised in one. One of the babies was treated with gentamicin and ampicillin initially followed by trimethoprimsulphamethoxazole when the diagnosis became clear, and the other with sulfisoxazole, and they both recovered.

It is of interest that the mothers of all three babies described in these two papers gave a history of vaginal discharge towards the end of pregnancy; $C$. trachomatis was recovered from the cervix of one of these women.

In the third of the papers reviewed, Schachter et al., from San Francisco, describe 12 infants from whom chlamydiae had been recovered. Seven had ocular chlamydial infection. Two of six female infants tested for vaginal infection yielded chlamydiae, and both had synchronous chlamydial conjunctivitis. Chlamydiae were recovered from the respiratory tract of five infants, four from nasopharyngeal or throat swabs or both, and one from lung biopsy material. Two other infants with radiologically confirmed pneumonia yielded chlamydiae only from the rectum. The authors suggest that the timing of recovery indicates that the vagina and conjunctivae are exposed to chlamydiae at birth and that pneumonia and gastrointestinal infection occurs later; rectal specimens may be useful for the diagnosis of chlamydial disease in infants.

Finally, Harrison et al. from the University of Washington, Seattle, describe the intratracheal, nasopharyngeal, and oropharyngeal inoculation of three infant baboons with a strain of $C$. trachomatis isolated from a human infant with pneumonia. One animal showed a persistent nasopharyngeal chlamydial infection, radiological evidence of pneumonia, and histological changes almost identical to those seen in human neonatal chlamydial pneumonia. The second baboon maintained nasopharyngeal chlamydiae for $\mathbf{3 0}$ days (when it was killed) and had a patchy mild pneumonitis at 
necropsy, and the third maintained nasopharyngeal chlamydiae for $\mathbf{4 9}$ days. All three animals showed seroconversion. The authors suggest that infant baboons may be a useful animal model for $C$. trachomatis nasopharyngitis and pneumonia.

J. D. Oriel

Beem, M. O. and Saxon, E. M. (1977). Respiratory tract colonisation and a distinctive pneumonia syndrome in infants infected with Chlamydia trachomatis. New England Journal of Medicine, 296, 306-310.

Frommell, G., Bruhn, F. W., and Schwartzman, J. D. (1977). Isolation of Chlamydia trachomatis from infan lung tissue. New England Journal of Medicine, 296, $1150-1152$.

Experimental infections of the chimpanzee urethra and pharynx with Chlamydia trachomatis

N. F. JACOBS, E. S. ARUM, AND S. J. KRAUS (1978). Sexually Transmitted Diseases 5, 132-136

An isolate of Chlamydia trachomatis obtained from a man with nongonococcal urethritis was used to produce experimental urethral and pharyngeal infections in chimpanzees. After urethral inoculation of only $8 \times 10^{1}$ inclusion-forming units (IFU), infections were established in three of three animals; urethral discharges developed in two. The infections persisted for five to nine weeks. Larger inocula $\left(7 \times 10^{2}\right.$ and $1 \times 10^{5}$ IFU) produced pharyngeal infections in two animals. The third animal's pharynx was not infected by $1 \times 10^{5}$ IFU. Chlamydial complementfixing antibodies increased significantly in sera of two of three animals. This study provides an animal model for study of mucosal infection by $C$. trachomatis. This relative resistance of the chimpanzee pharynx to infection parallels clinical observations in man.

Authors' summary

Serological response of patients with nongonococcal urethritis to causative organism of contagious equine metritis 1977

C. E. D. TAYLOR, R. O. ROSENTHAL, AND D. TAYLOR-ROBINSON (1979). Lancet, 1 , 700-701

The presence of agglutinins to the causative organism of contagious equine metritis (CEM) in human serum has been confirmed. Agglutinins were found in the serum of $84(37 \cdot 6 \%)$ of 223 patients with nongonococcal urethritis (NGU), and in $12.5 \%$ of these patients there was a fourfold or greater rise in titre during the course of their illness. There was no evidence that these agglutinins were the result of infection by chlamydiae or ureaplasmas. Certain patients with these agglutinins seemed to respond better to therapy with antibiotics to which the CEM bacterium is susceptible in vitro than did patients in whom these agglutinins were not found. The findings suggest that the CEM bacterium or a microorganism related to it may be aetiologically involved in a proportion of patients with NGU. A search for such an organism in these patients is in progress.

$$
\text { Authors' summary }
$$

Clinical and microbiological investigation of men with urethritis

Y-H. LEE, B. ROSNER, S. ALPERT, N. J. FIUMARA, AND W. M. MCCORMACK (1978). Journal of Infectious Diseases, 138, 798-803

Chlamydia trachomatis urethritis in men attending a venereal disease clinic: a culture and therapeutic study

K. T. RIPA, P.-A. MÅDH, AND I. THELIN (1978). Acta Dermatovenereologica, 58, 175-179

Chlamydiae, cervicitis, and abnormal Papanicolaou smears

M. C. CARR, L. HANNA, AND E. JAWETZ (1979). Obstetrics and Gynecology, 53, 27-30

Chlamydial pneumonia and human sexuality (leading article)

R. B. GOLDBLOOM (1978). Canadian Medical Association Journal, 119, 1153-1154

Experimental acute salpingitis in grivet monkeys provoked by Chlamydia trachomatis

K. T. RIPA, B. R. MELLER, P.-A. MÅRDH, E. A. FREUNDT, AND F. MELSEN (1979). Acta Pathologica et Microbiologica Scandinavica, 87, 65-70

Cultivation of Ureaplasma urealyticum in continuous culture

G. MASOVER, R. PEREZ, AND A. MATIN (1979). Infection and Immunity, 23, 175

\section{Trichomoniasis}

Strain of Trichomonas vaginalis resistant to metronidazole and other 5-nitroimmidazoles

J. G. MEINGASSNER AND J. THURNER (1979). Antimicrobial Agents and Chemotherapy, 15, 254-255

\section{Candidosis}

Vulvovaginal candidiasis in pregnancy treated with clotrimazole

K. HARAM AND A. DIGRANES (1978). Acto Obstetriciaand Gynecologica Scandinavica 57, 453-456

\section{Genital herpes}

Clinical course and diagnosis of genital herpes simplex virus infection and evaluation of topical surfactant therapy L. A. VONTVER, W. C. REEVES, M. RATTRAY, L. COREY, M. A. REMINGTON, E. TOLENTINO A. SCHWEID, AND K. K. HOLMES (1979). American Journal of Obstetrics and Gynecology, 133, 548-554

A prospective study of 37 men and 32 women with culture-proved genital herpes simplex virus (HSV) infection was undertaken to characterise the clinica manifestations of the disease and effects of topical therapy with Nonoxynol 9 , a nop ionic surfactant active in vitro against HSK The duration of pain, lesions, and virg shedding was significantly longer in initia than in recurrent genital HSV infection Cervical HSV shedding occurred in 11 of 17 initial infections versus two of $1 \&$ recurrences $(\mathrm{P}<0 \cdot 001)$. Type $1 \mathrm{HSV}$ caused seven of 29 initial and none of 40 recurren infections $(P<0 \cdot 01)$. Clinical recurrences within six weeks were detected more ofte in men than in women and were unrelated to the menstrual cycles. The influence of coitus on recurrences is uncleaf? Papanicolaou smears were transiently abnormal (Class II) in four $(12 \cdot 5 \%)$ of $3 \frac{3}{6}$ female patients. Evidence of herpesvirus was detected in cytological smears from only $28(41 \%)$ of 69 culture-proved externa lesions and three $(23 \%)$ of 13 culture 
positive cervices. Serology was also of limited diagnostic value except in testing paired sera from initial infections. The topical therapy had no beneficial effect.

Authors' summary

Treatment of genital herpes simplex virus infection with photodynamic inactivation R. H. KAUFMAN, E. ADAM, R. R. MIRKOVIC, J. MELNICK, AND R. L. YOUNG (1978). American Journal of Obstetrics and Gynecology, 132, 861-869

Herpes virus fingerprinting (leading article) Lancet, 1979, 1, 251-252

\section{Other sexually transmitted diseases}

\section{Epidemic of chancroid in Greenland 1977-1978}

T. LYKKE-OLESEN, T. G. PEDERSEN, L. LARSEN, AND K. GAARSLEV (1979). Lancet, 1, 654-655

In Greenland there has been a rapid increase in the incidence of gonorrhoea and syphilis during past decades. In 1977 there was an epidemic of chancroid along the west coast of Greenland, with 975 cases reported from some 32500 adults. The number of reported cases increased until October, 1977, and subsequently decreased. A total of 186 patients was studied. Many of these had previously had gonorrhoea and syphilis. Male patients were both Eskimoan and Danish but female patients were solely Eskimoan. The sex ratio (M/F) was 1-6:1. The incubation period was four days in men and 13 days in women. Symptomfree female carriers did not seem to be an important reservoir of infection. Fifteen per cent of the patients were admitted to hospital with buboes or extensive lesions. The clinical course was uncomplicated in most cases. Ulcers healed within a week of treatment with sulphonamide. Chancroid can be expected to disappear in Greenland within a short time.

Authors' summary

Human wart virus antibodies in patients with genital and skin warts

S. PYRHÖNEN (1978). Acta Dermatovenereologica (Stockholm), 58, 427-432

A comparative follow-up study of the antibody response against human wartvirus was performed using the immunodiffusion and complement fixation methods on patients with condylomas and skin warts. By the immunodiffusion method, $13 \%$ of the patients with skin warts and $3 \%$ of the patients with condylomas showed $>$ fourfold increase of antibody titre during the follow-up of 2-35 months. The findings show some typical features of the weak antibody response of a chronic viral infection and suggest a serological overlapping between condyloma viruses and certain group of skin wart-viruses. The antibody prevalence in age-matched controls is shown to be significantly higher than that in the wart or condyloma patients' initial serum samples. This is indicative of the protective function of antibodies against warts and condylomas. Also the analysis of the history of warts in patients with condylomas suggests that protection against condylomas can be acquired from previous warts, evidently by immunological mechanisms. In a control group of medical students, human wartvirus antibodies were frequently $(52 \%)$ found in subjects without any history of warts. This finding supports the view that human wart-virus can frequently induce latent or subclinical infections in human beings.

Author's summary

The beneficial effects of $1 \% 5$-fluorouracil in $70 \%$ ethanol on therapeutically refractory condylomas in the preputial cavity

G. VON KROGH (1978). Sexually Transmitted Diseases, 5, 137-140

The effect of two daily applications of $1 \%$ 5-fluorouracil (5-FU) in $70 \%$ ethanol on penile condylomas was investigated in 65 men. Complete cures were obtained in $37 \%$ and marked regression in $42 \%$ of the patients. The most pronounced effect was seen on warts in the preputial cavity and on the adjacent foreskin, where the efficacy of $1 \%$ 5-FU in ethanol was comparable to that of $5 \% 5$-FU cream. However, the pronounced side effects observed with use of the 5-FU cream were reduced to negligibility by use of an alcoholic vehicle for the drug. Patients who have therapeutically refractory condylomas in or near the preputial cavity should receive one or more courses of treatment with $1 \% 5$-FU in ethanol. With regard to meatal warts, the effect of two daily applications of 5\% 5-FU cream for two weeks was found to be therapeutically inferior compared with results of previous studies in which the same treatment was extended for three to four weeks.

\section{Liver disease among homosexual males}

W. R. ELLIS, I. M. MURRAY-LYON,

J. C. COLEMAN, B. A. EVANS, J. L. FLUKER,

J. BULL, P. W. N. KEELING, P. D. SIMMONS,

J. E. BANATVALA, J. R. WILlCOX, AND

R. P. H. THOMPSON (1979). Lancet, 1 , 903-905

A survey of 2612 homosexual men for the presence of hepatitis B surface antigen (HBsAg) yielded positive results in 129 $(4 \cdot 94 \%)$ of the men. This incidence is 50 times greater than that found in blood donors in the United Kingdom. Sixty-five of the HBsAg-positive patients were tested for abnormal liver function tests (LFTs), of which 43 proved to have impairment. Twenty-five of the abnormal LFT group had a liver biopsy, of which 14 showed chronic active hepatitis and the remaining 11 minor inactive liver disease. Of 118 HBsAg-positive males examined for e antigen ( $\mathrm{HBeAg}), 38 \%$ had positive results. There was no correlation between $\mathrm{HBeAg}$ positive patients and chronic active hepatitis, over half the patients with inactive liver disease having positive results for this antigen. This result contrasts with a report by others of $13 \%$ of $\mathrm{HBsAg}$-positive heterosexual men being also $\mathrm{HBeAg}$ positive.

The important recommendation of this paper is that $\mathrm{HBs} \mathbf{A g}$-positive patients with abnormal liver function tests should be subjected to liver biopsy. By implication, it would appear that all admitted homosexual men should be tested for $\mathrm{HBsAg}$ on attendance.

\section{G. L. Ridgway}

Antibodies against chlamydiae of lymphogranuloma-venereum type in Crohn's disease

J. L. SCHULLER, J. PIKET-VAN ULSEN,

I. V. D. VEEKEN, M. F. MICHEL, AND E. STOLZ (1979). Lancet, 1, 19-20

Antibodies against Chlamydia of lymphogranuloma venereum type were detected by the microimmunofluorescence technique in $38(69 \%)$ of 55 patients with Crohn's disease. Weak positive reaction were seen in only two of 21 patients with other gastrointestinal disorders and in one of 50 healthy blood donors.

Authors' summary 
Low frequency of chlamydial antibodies in patients with Crohn's disease and ulcerative colitis

D. TAYLOR-ROBINSON, C. S. O'MORAIN,

B. J. THOMAS, AND A. J. LEVI (1979). Lancet,

1, 1162-1163

Serum samples from 55 patients with Crohn's disease and from 23 patients with ulcerative colitis were tested for antibodies to Chlamydia trachomatis immunotypes by micro-immunofluorescence technique. Antibody titres of $1 / 8$ or greater against several immunotypes were detected in $14.5 \%$ of patients with Crohn's disease and in $21.7 \%$ of those with ulcerative colitis. These figures resemble the incidence in a healthy, non-venereal disease population. Furthermore, there was no correlation between the presence of antibody and such factors as duration of symptoms, localisation of disease, or disease activity. These findings indicate that there is no reason to believe that Crohn's disease involves chlamydiae or that examination for chlamydial antibody is helpful in diagnosis.

Authors' summary

Salient features of Haemophilus vaginalis J. R. GREENWOOD AND M. J. PICKETT (1977). Journal of Clinical Microbiology, 9, 200-204

Factors affecting isolation and identification of Haemophilus vaginalis (Corynebacterium vaginale)

R. K. BAILEY, J. L.. VOSS, AND R. F. SMITH (1979). Journal of Clinical Microbiology, 9, 65-71

These two papers deal with the laboratory aspects of isolation and identification of Haemophilus vaginalis.

Greenwood and Pickett tested 78 strains and give recommendations for laboratory identification. Bailey et al. report on isolation procedures, finding that anaerobiasis is not required for primary isolation and that a six-hour delay before plating does not reduce the isolation rate.
This paper also assesses the behaviour of this organism in some of the commercially available identification systems.

These papers are of interest to those laboratory workers who wish to differentiate $\boldsymbol{H}$. vaginalis from other Gramnegative vaginal flora.

M. C. Kelsey

Bacteriology of acute pelvic inflammatory disease

A. W. CHOW, V. PATTEN, AND J. R. MARSHALL (1979). American Journal of Obstetrics and Gynecology, 133, 362-365

The bacteriology of acute pelvic inflammatory disease (PID) was studied in 20 patients by simultaneous cul-de-sac, cervical, and blood cultures with aerobic and fastidious anaerobic techniques. Culde-sac cultures gave positive results in 18 of 20 patients while all eight normal control subjects yielded negative results $(P<0 \cdot 0005$, $\chi^{2}$ analysis.). Anaerobic bacteria (predominantly Peptococcus and Peptostreptococcus) were present in 10 $(59 \%)$ patients, and they were the exclusive isolates in three patients. Neisseria gonorrhoeae was isolated only once from the cul-de-sac despite its presence in cervical specimens. There was poor correlation between cul-de-sac and cervical cultures. Cervical cultures yielded a variety of aerobic and anaerobic bacteria with an average of 3.8 organisms per specimen. $N$. gonorrhoeae was isolated in $13(65 \%)$ patients. Only $19 \%$ of cervical isolates were recovered by culdocentesis; similarly, only $31 \%$ of cul-de-sac isolates were simulataneously isolated from the cervix. Blood cultures were uniformly negative. These data suggest that: (1) culdocentesis is a reliable technique for the bacteriological diagnosis of acute PID, and (2) whereas the gonococcus may be important in initiating acute PID its primary role appears to be paving the way for secondary invaders from the normal vaginal flora to gain acess to the upper genital tract.

Authors' summary
Genital mycoplasmas and birth weight in $\stackrel{\overparen{D}}{\frac{D}{D}}$ offspring of primigravid women R. F. HARRISON, R. HURLEY, AND J. DELOUV ( (1979). American Journal of Obstetrics $a_{i} \vec{\nexists}$ Gynecology, 133, 201-203

The relationship between colonisation pregnant women by Ureaplasma are Mycoplasma and the outcome of pregnan $\mathbb{D}$ in a study of 104 women is reported. The were eight abortions but no multiple birt or stillbirths. Excluding abortions, th mean gestational length was 39.6 week. and the corrected mean birth weight w $\overrightarrow{\mathrm{d}}$ $3.28 \mathrm{~kg}$. There was no relationship between maternal colonisation by genit mycoplasmas and reduction in birth weig of the offspring, but five of the eight women who aborted harboured Ureaplasma, suggesting an increased tren toward abortion in women harbouring Ureaplasma.

Authors' summary

Sexually transmitted infections in homosexual men R. R. BABB (1979). Postgraduate Medicine,, 0 65, 215-222

Natural history and prevention of hepatif $B$ re-examined

S. KRUGMAN, L. R. OVERBY, I. K. MUSHAHWAR C-M. LING, G. G. FROSNER, AND F. DEINHARDP (1979). New England Journal of Medicine 300, 101-105

Behcet's syndrome associated with pregnancy

W. G. HURT, C. L. COOKE, W. P. JORDAN, J. P. BULLOCK JUN., AND G. E. RODRIGUEZ (1979). Obstetrics and Gynecology, 55 (Supplement) 31S-33S

Penile venereal edema R. A. WRIGHT AND F. N. JUDSON (1979). Journal of the American Medical Association, 241, 157 